Supporting Information

\title{
Design Guidelines for Rigid Epoxy Resins with High Photon Upconversion Efficiency: Critical Role of Emitter Concentration
}

Tsubasa Kashino, ${ }^{\dagger}, \stackrel{+}{ }$ Rena Haruki, ${ }^{\dagger,}$ Masanori Uji, ${ }^{\dagger}$ Naoyuki Harada, ${ }^{\dagger}$ Masanori Hosoyamada, ${ }^{\dagger}$ Nobuhiro Yanai ${ }^{*}, \dot{\dagger}, \#$ and Nobuo Kimizuka ${ }^{*}, \dagger$

$\uparrow$ Department of Applied Chemistry, Graduate School of Engineering, Center for Molecular Systems (CMS), Kyushu University, 744 Moto-oka Nishi-ku, Fukuoka 819-0395, Japan.

\$ Nissan Chemical Corporation, Funabashi 274-0069, Japan.

\# JST-PRESTO, Honcho 4-1-8, Kawaguchi, Saitama 332-0012, Japan.

E-mail: yanai@mail.cstm.kyushu-u.ac.jp,n-kimi@mail.cstm.kyushu-u.ac.jp 


\section{Characterization.}

The ${ }^{1} \mathrm{H}-\mathrm{NMR}(500 \mathrm{MHz})$ spectra were measured on a Bruker Ascend ${ }^{\mathrm{TM}} 500$ spectrometer using TMS as the internal standard. The LC-MS measurements were performed by an AB SCIEX Triple TOF 5600+ instrument. Elemental analysis was conducted with a J-Science JM10 instrument, and FT-IR spectra were recorded on a SHIMADZU IRAffinity-1S Fourier transform infrared spectrophotometer. Differential scanning calorimetry (DSC) was performed in a NETSCH Japan K.K. DSC 204 F1 Phoenix ${ }^{\circledR}$. Dynamic mechanical analysis (DMA) was done with a T. A. instruments Japan Co. Q-800 instrument. The test dimensions of the cured film were $4 \mathrm{~mm}$ width, $20 \mathrm{~mm}$ length, and $0.2 \mathrm{~mm}$ thickness. UV-vis-NIR absorption spectra were recorded on a SHIMADZU UV-3600 spectrophotometer while fluorescence spectra were measured by using a Hitachi High-Tech Science Co. F-7000 spectrometer. A $375 \mathrm{~nm}$ diode laser $(75 \mathrm{~mW}$, RGB Photonics) was used as a $375 \mathrm{~nm}$ light source for the temperature dependence of the fluorescence intensity. 


\section{Determination of relative TTA-UC quantum efficiency.}

The TTA-UC efficiencies $\eta_{\mathrm{UC}}$ of films were determined relative to Nile red in a cured epoxy film according to the following equation, ${ }^{1}$

$$
\eta_{\mathrm{UC}}=2 \Phi_{\mathrm{std}}\left(\frac{1-10^{-A_{\mathrm{std}}}}{1-10^{-A_{\mathrm{UC}}}}\right)\left(\frac{E_{\mathrm{UC}}}{E_{\mathrm{std}}}\right)\left(\frac{I_{\mathrm{std}}}{I_{\mathrm{UC}}}\right)\left(\frac{n_{\mathrm{UC}}}{n_{\mathrm{std}}}\right)^{2}
$$

where $\Phi, A, E, I$ and $n$ represent the quantum yield, absorbance at $532 \mathrm{~nm}$, integrated photoluminescence spectral profile, excitation intensity, and the refractive index of the films, respectively. The subscripts UC and std denote the parameters of the upconversion and standard systems. Since the standard and the UC films are based on identical epoxy resin, the refractive index ratio is approximated as 1 . The absolute fluorescence quantum yield of Nile red in the cured film was 0.82 . Note the maximum $\eta \mathrm{UC}$ is normalized to $100 \%$ by multiplying the TTA-UC quantum yield (50\% maximum) by 2 .

\section{Determination of TET efficiency.}

The sensitizer-to-emitter TET efficiency was quantified by measuring phjosphorescence quantum yields of the films and a cured film containing only PtOEP without emitter (film 11). The TET efficiency $\Phi_{\text {TET }}$ was estimated by the following equation,

$$
\Phi_{\mathrm{TET}}=1-\frac{\Phi_{\mathrm{P}}}{\Phi_{\mathrm{P}, 0}}
$$

where $\Phi_{\mathrm{P}}$ and $\Phi_{\mathrm{P}, 0}$ represent phosphorescence quantum yields of the film with and without the emitter, respectively. 


\section{Materials.}

Scheme S1. Chemical structure of Epoxy A (Hydrogenated bisphenol A-glycidyl ether).

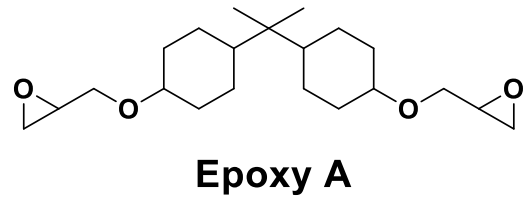

Synthesis of Epo-DPA

All reaction solvents for synthesis and cesium carbonate $\left(\mathrm{Cs}_{2} \mathrm{CO}_{3}\right)$ were purchased from Junsei Chem. 9,10-dibromoanthracene (DBA), [1,3-Bis(2,6-Diisopropylphenyl)imidazole-2-ylidene](3chloropyridyl)palladium(II) dichloride (PEPPSI ${ }^{\mathrm{TM}}$-IPr) were purchased from Aldrich Co. 4methoxycalbonylphenylboronic acid, ethylene glycol monoallyl ether (Allyl-OH) and triethylamine were purchased from Tokyo Chem. Ind. Co., Ltd. 6 mol L ${ }^{-1}$ hydrochloric acid $(6 \mathrm{~N}$ $\mathrm{HCl}$ aq.), potassium hydroxide $(\mathrm{KOH}), m$-chloroperoxybenzoic acid ( $m$-CPBA), 1-(3dimethylaminopropyl)-3-ethylcarbodiimide hydrochloride (WSC $\mathrm{HCl}$ ) and 1hydroxybenzotriazole (HOBt) were purchased from FUJIFILM Wako Pure Chem. Co.

Scheme S2 Synthetic routes of Epo-DPA
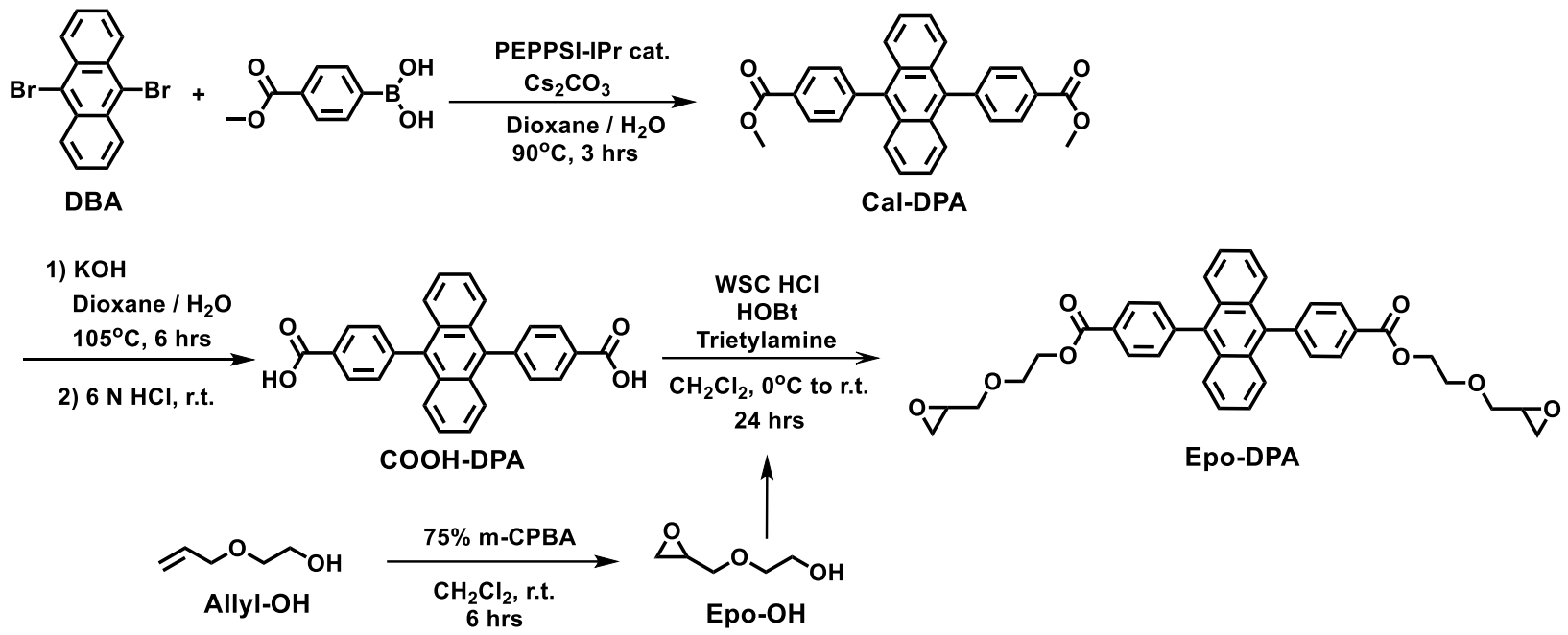

Synthesis of 9,10-(4-methoxycalbonylphenyl) anthracene (Cal-DPA): It was synthesized by slightly modifying the reported procedure ${ }^{2-4}$. In a $2000 \mathrm{~mL}$ of 4-neck flask, DBA (24.9 g, 74.0 mmol), 4-methoxycalbonylphenylboronic acid (31.6 g, $162.8 \mathrm{mmol})$ and $900 \mathrm{~mL}$ of 1,4-dioxane were added and stirred under nitrogen atmosphere at $90^{\circ} \mathrm{C}$. PEPPSI ${ }^{\mathrm{TM}}-\mathrm{IPr}(0.5 \mathrm{~g}, 0.74 \mathrm{mmol})$ in $100 \mathrm{~mL}$ of 1,4-dioxane and $\mathrm{Cs}_{2} \mathrm{CO}_{3}(53.0 \mathrm{~g}, 162.8 \mathrm{mmol})$ in $100 \mathrm{~mL}$ of distilled water were added to the mixture respectively and reacted for $3 \mathrm{~h}$ at $90{ }^{\circ} \mathrm{C}$ until complete disappearance of the DBA (monitored by TLC). After the mixture was cooled to room temperature, $500 \mathrm{~mL}$ of distilled water was added with stirring. The precipitate was filtered and washed with distilled water. The precipitate was extracted with $\mathrm{CHCl}_{3}$ for three times. The solvent was removed under reduced pressure and the residue was reprecipitated by acetonitrile to give the Cal-DPA ( $27.8 \mathrm{~g}, 62.3 \mathrm{mmol}$, 
84\%). ${ }^{1} \mathrm{H}-\mathrm{NMR}\left(500 \mathrm{MHz}, \mathrm{CDCl}_{3}\right) \delta:(\mathrm{ppm})=4.02(\mathrm{~s}, 6 \mathrm{H}), 7.35(\mathrm{dd}, 4 \mathrm{H}), 7.57(\mathrm{~d}, 4 \mathrm{H}), 7.62(\mathrm{dd}$, $4 \mathrm{H}), 8.29(\mathrm{~d}, 4 \mathrm{H})$.

Synthesis of 9, 10-(4-calboxyphenyl) anthracene ${ }^{2-4}$ (COOH-DPA): KOH (31.4 g, 560 mmol) was dissolved in $100 \mathrm{~mL}$ of pure water. It was added to a mixture of Cal-DPA (25.0 g, $56.0 \mathrm{mmol})$ in $400 \mathrm{~mL}$ of 1,4-dioxane. The mixture was stirred under reflux for $6 \mathrm{~h}$ until complete disappearance of the Cal-DPA (monitored by TLC). After that, $200 \mathrm{~mL}$ of distilled water was added to the residue and cooled to room temperature. $6 \mathrm{~N} \mathrm{HCl}$ aq. was added to the suspension until the $\mathrm{pH}$ value was adjusted to 2 . The precipitate was filtered and washed with water to give the COOH-DPA (22.96 g, 54.9 mmol, 98\%). ${ }^{1} \mathrm{H}-\mathrm{NMR}(500 \mathrm{MHz}$, dimethysulfoxide-d6) 7.45 (dd, 4H), 7.56 (dd, 4H), $7.62(\mathrm{~d}, 4 \mathrm{H}), 8.22(\mathrm{~d}, 4 \mathrm{H}), 13.1(\mathrm{~s}, 2 \mathrm{H})$.

Synthesis of ethylene glycol monoglycidyl ether (Epo-OH): Allyl-OH (20.4 g, $200 \mathrm{mmol}$ ) and $m$-CPBA (70\% in water, $59.2 \mathrm{~g}, 240 \mathrm{mmol}$ ) were dissolved in $300 \mathrm{~mL}$ of dichloromethane. The reaction mixture was stirred at room temperature for $6 \mathrm{~h}$ until complete disappearance of the Allyl$\mathrm{OH}$ (monitored by GC). After that, the solvent was removed under reduced pressure. The reacted $m$-CPBA precipitate was filtered, and the filtrate was purified by flash column chromatography (eluent : ethyl acetate) to give Epo-OH (17.7 g, $150 \mathrm{mmol}, 60 \%) .{ }^{1} \mathrm{H}-\mathrm{NMR}\left(500 \mathrm{MHz}, \mathrm{CDCl}_{3}\right) \delta$ : $(\mathrm{ppm})=2.1(\mathrm{t}, 1 \mathrm{H}), 2.65(\mathrm{dd}, 1 \mathrm{H}), 2.82(\mathrm{t}, 1 \mathrm{H}), 3.12(\mathrm{~m}, 1 \mathrm{H}), 3.46(\mathrm{dd}, 1 \mathrm{H}), 3.61(\mathrm{~m}, 1 \mathrm{H}), 3.66$ $(\mathrm{m}, 1 \mathrm{H}), 3.75(\mathrm{q}, 2 \mathrm{H}), 3.83(\mathrm{dd}, 1 \mathrm{H})$.

Synthesis of 9,10-(4-ethylene glycol monoglycidyl ether) anthracene (Epo-DPA): In a roundbottomed flask, COOH-DPA (10.5 g, $25 \mathrm{mmol})$, Epo-OH (7.1 g, $60 \mathrm{mmol})$ and triethylamine (15.2 $\mathrm{g}, 150 \mathrm{mmol})$ were dissolved in $200 \mathrm{~mL}$ of dichloromethane. A mixture of WSC $\mathrm{HCl}(11.5 \mathrm{~g}, 60$ $\mathrm{mmol}$ ), HOBt ( $8.1 \mathrm{~g}, 60 \mathrm{mmol})$ and $100 \mathrm{~mL}$ of dichloromethane was added slowly to the reaction mixture with stirring in an ice bath. After that, the mixture was stirred at room temperature for a day. It was washed with $5 \mathrm{wt} \% \mathrm{NaHCO}_{3}$ aq., $10 \mathrm{wt} \% \mathrm{NH}_{4} \mathrm{Cl}$ aq. and brine. The Organic layer was dried with $\mathrm{MgSO}_{4}$ and removed under reduced pressure. The residue was purified by flash column chromatography (eluent: dichloromethane : ethyl acetate, $90: 10(\mathrm{v} / \mathrm{v}))$ to give pure Epo-DPA (8.8 g, $13.1 \mathrm{mmol}, 52.5 \%) .{ }^{1} \mathrm{H}-\mathrm{NMR}\left(500 \mathrm{MHz}, \mathrm{CDCl}_{3}\right): \delta:(\mathrm{ppm})=2.67(\mathrm{dd}, 2 \mathrm{H}), 2.84(\mathrm{t}, 2 \mathrm{H}), 3.23$ $(\mathrm{m}, 2 \mathrm{H}), 3.53(\mathrm{dd}, 2 \mathrm{H}), 3.91(\mathrm{~m}, 4 \mathrm{H}), 3.95(\mathrm{~m}, 2 \mathrm{H}), 4.59(\mathrm{~m}, 4 \mathrm{H}), 7.35(\mathrm{dd}, 4 \mathrm{H}), 7.58(\mathrm{~d}, 4 \mathrm{H}), 7.63$ $(\mathrm{dd}, 4 \mathrm{H}), 8.32$ (d, 4H). Elemental analysis, calculated for $\mathrm{C}_{38} \mathrm{H}_{34} \mathrm{O} 8: \mathrm{C}, 73.77$; H, 5.54; O, 20.69; N, 0.00; found: C, 73.49; H, 5.54; O, 20.82; N, 0.01. LC-MS, calculated for $\mathrm{C}_{38} \mathrm{H}_{34} \mathrm{O}_{8}, 618.22$, found $619.23\left(\mathrm{M}+\mathrm{H}^{+}\right)$. 

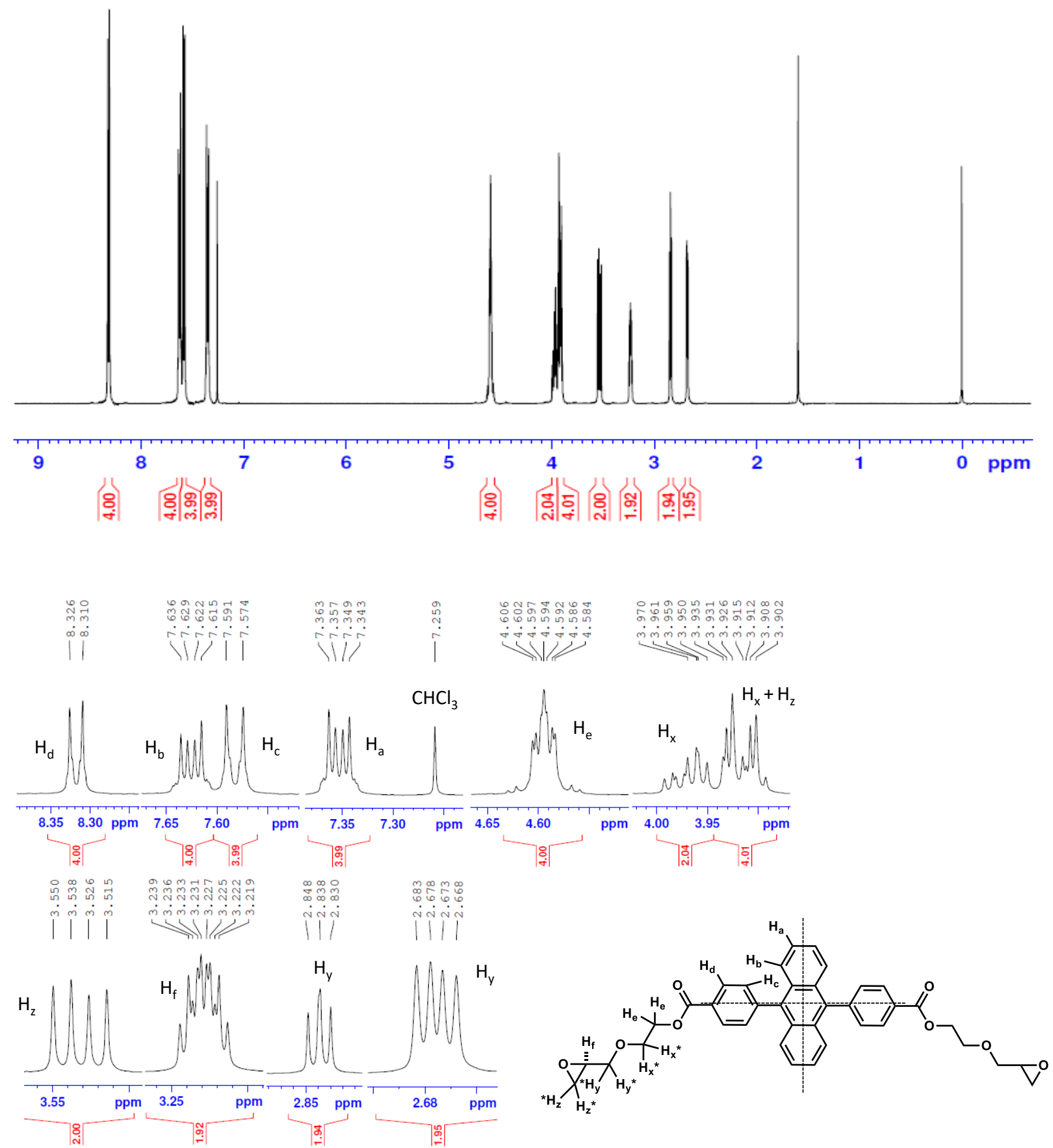

${ }^{1} \mathrm{H}-\mathrm{NMR}$ spectra $\left(500 \mathrm{MHz}, \mathrm{CDCl}_{3}\right.$, TMS) of Epo-DPA. The upper graph displays whole spectrum and the below graph shows the expansion of each peaks and these assignments. 

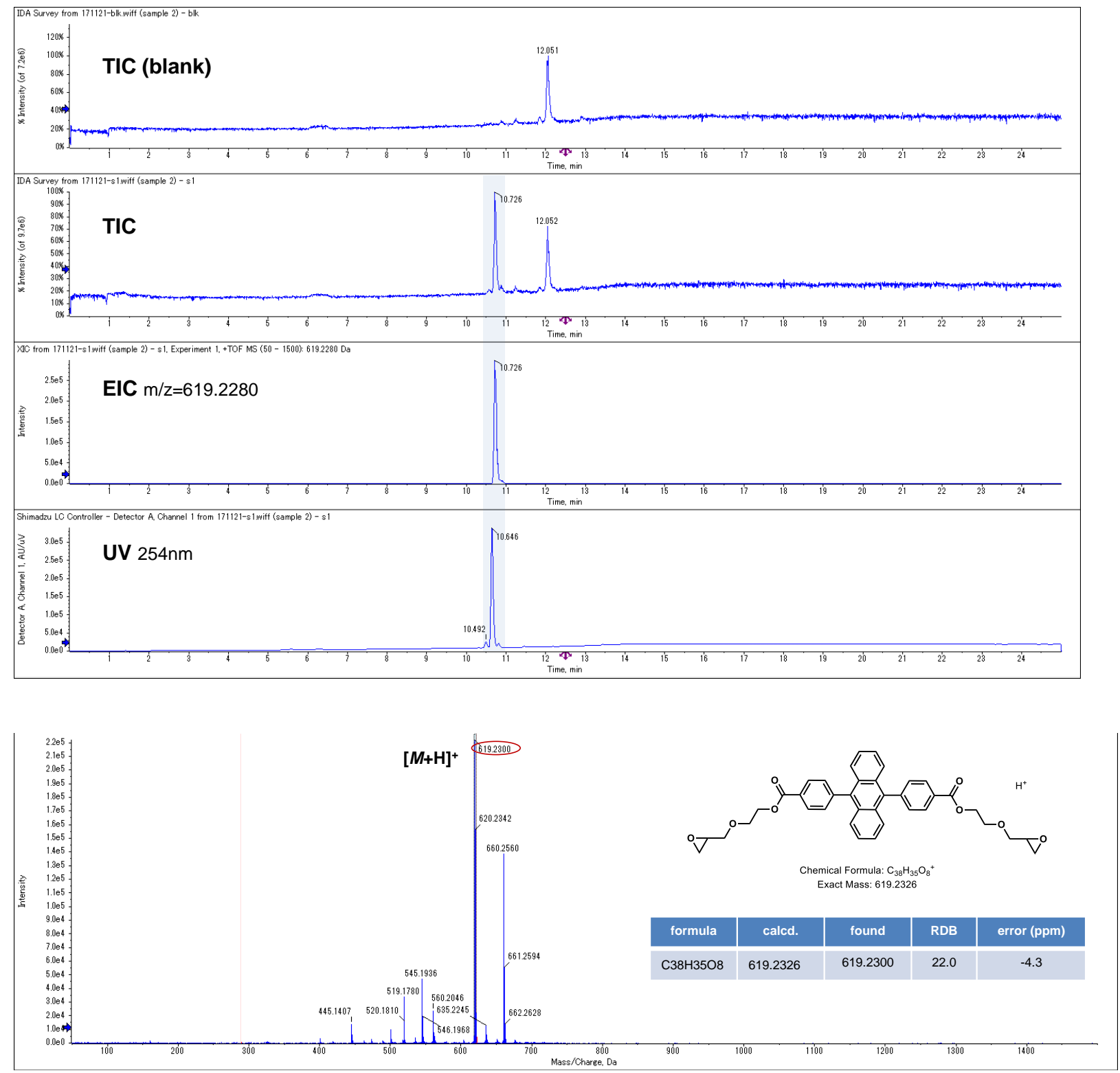

LC-MS analysis of Epo-DPA. TIC means total ion chromatography and EIC is extracted ion chromatography, respectively. 
Table S1. The contents of the liquid precursors for the films 1-14. The DPA unit concentration $(\mathrm{wt} \%$ ) was calculated by (the total weight of DPA unit/the total amount of precursor) $\times$ 100. A catalytic amount of reaction promoter (tetrabutylphosphonium $O, O$-diethylphosphoro dithioate) was added to the precursors 11-14.

\begin{tabular}{|c|c|c|c|c|c|c|}
\hline \multirow[b]{2}{*}{ films } & \multicolumn{5}{|c|}{ materials / weight, mol\% } & \multirow[b]{2}{*}{$\begin{array}{l}\text { DPA uni } \\
\text { amount } \\
\text { (wt\%) }\end{array}$} \\
\hline & $\begin{array}{l}\text { PtOEP } \\
(\mathrm{mg}) \\
(\mathrm{mol} \%)\end{array}$ & $\begin{array}{c}P_{66614} \text { DPAS } \\
(\mathrm{mg}) \\
(\mathrm{mol} \%)\end{array}$ & $\begin{array}{c}\text { Epo-DPA } \\
\qquad(\mathrm{mg}) \\
(\mathrm{mol} \%)\end{array}$ & $\begin{array}{c}\text { Epoxy A } \\
\text { (mg) } \\
(\mathrm{mol} \%)\end{array}$ & $\begin{array}{c}\text { Acid anhydride } \\
\qquad \begin{array}{c}\text { (mg) } \\
(\mathrm{mol} \%)\end{array}\end{array}$ & \\
\hline \multirow{2}{*}{ film 1} & 0.00723 & 89.3 & 92.8 & \multirow{2}{*}{0} & 49.5 & \multirow{2}{*}{35.6} \\
\hline & 0.01 & 100 & 150 & & 300 & \\
\hline \multirow{2}{*}{ film 2} & 0.00723 & 89.3 & 69.5 & 13.2 & 49.5 & \multirow{2}{*}{31.6} \\
\hline & 0.01 & 100 & 112.5 & 37.5 & 300 & \\
\hline \multirow{2}{*}{ film 3} & 0.00723 & 89.3 & 46.4 & 26.5 & 49.5 & \multirow{2}{*}{27.3} \\
\hline & 0.01 & 100 & 75 & 75 & 300 & \\
\hline \multirow{2}{*}{ film 4} & 0.00723 & 89.3 & 23.2 & 39.7 & 49.5 & \multirow{2}{*}{22.5} \\
\hline & 0.01 & 100 & 37.5 & 112.5 & 300 & \\
\hline \multirow{2}{*}{ film 5} & 0.00723 & 89.3 & \multirow{2}{*}{0} & 52.9 & 49.5 & \multirow{2}{*}{17.2} \\
\hline & 0.01 & 100 & & 150 & 300 & \\
\hline \multirow{2}{*}{ film 6} & \multirow{2}{*}{0} & 89.3 & 92.8 & \multirow{2}{*}{0} & 49.5 & \multirow{2}{*}{35.6} \\
\hline & & 100 & 150 & & 300 & \\
\hline \multirow{2}{*}{ film 7} & \multirow{2}{*}{0} & 89.3 & 69.5 & 13.2 & 49.5 & \multirow{2}{*}{31.6} \\
\hline & & 100 & 112.5 & 37.5 & 300 & \\
\hline \multirow{2}{*}{ film 8} & \multirow{2}{*}{0} & 89.3 & 46.4 & 26.5 & 49.5 & \multirow{2}{*}{27.3} \\
\hline & & 100 & 75 & 75 & 300 & \\
\hline \multirow{2}{*}{ film 9} & \multirow{2}{*}{0} & 89.3 & 23.2 & 39.7 & 49.5 & \multirow{2}{*}{22.5} \\
\hline & & 100 & 37.5 & 112.5 & 300 & \\
\hline \multirow{2}{*}{ film 10} & \multirow{2}{*}{0} & 89.3 & \multirow{2}{*}{0} & 52.9 & 49.5 & 172 \\
\hline & & 100 & & 150 & 300 & 17.2 \\
\hline film 11 & 0.00723 & 0 & 0 & 52.9 & 49.5 & - \\
\hline fil $x$ & 0.00723 & 0 & 154.7 & 0 & 82.5 & 010 \\
\hline IIIIII IL & 0.01 & 0 & 250 & 0 & 500 & 34.0 \\
\hline film 13 & 0.00723 & 0 & 108.3 & 26.5 & 82.5 & 26 \\
\hline 1IIII & 0.01 & 0 & 175 & 75 & 500 & 20.0 \\
\hline film 14 & 0.00723 & 0 & 61.9 & 52.9 & 82.5 & 167 \\
\hline $\mathrm{Tllm} / 4$ & 0.01 & 0 & 100 & 150 & 500 & 10.1 \\
\hline
\end{tabular}




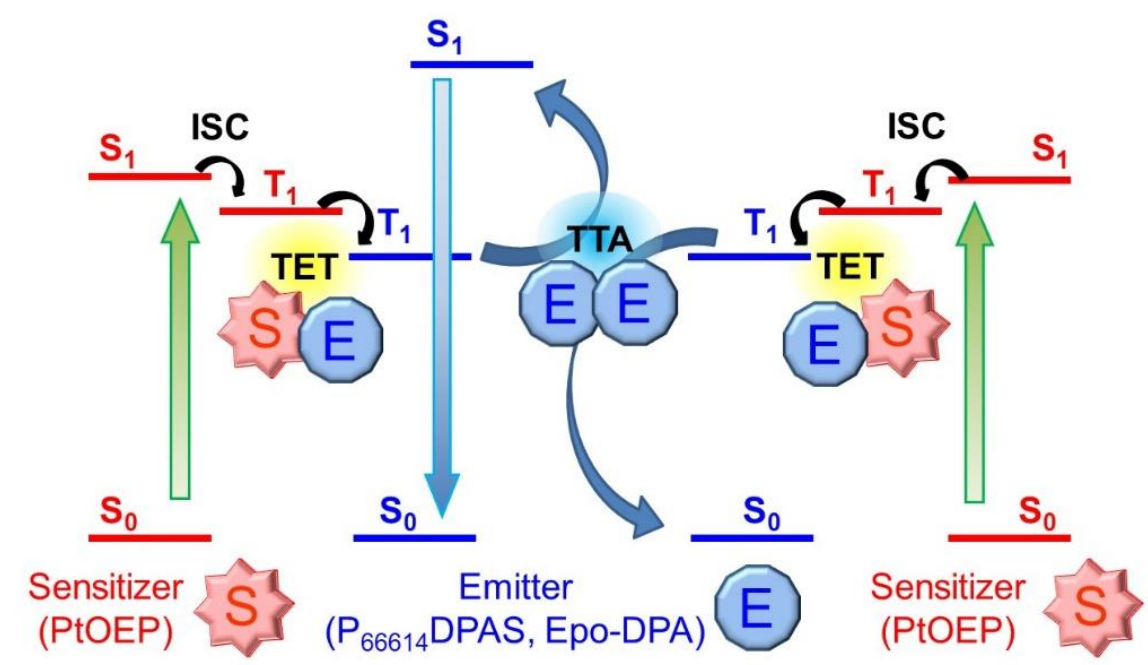

Figure S1. Schematic illustration for the TTA-UC process consisting of sensitizer/emitter pair. A photo-absorbed (green arrows) sensitizer undergoes intersystem crossing (ISC) and occurs triplettriplet energy transfer (TET) to the emitter. A pair of the triplet-excited emitters occur triplet-triplet annihilation (TTA) and then generates a singlet-excited emitter. The shorter wavelength UC emission (blue arrows) is observed from the longer sensitizer absorption.

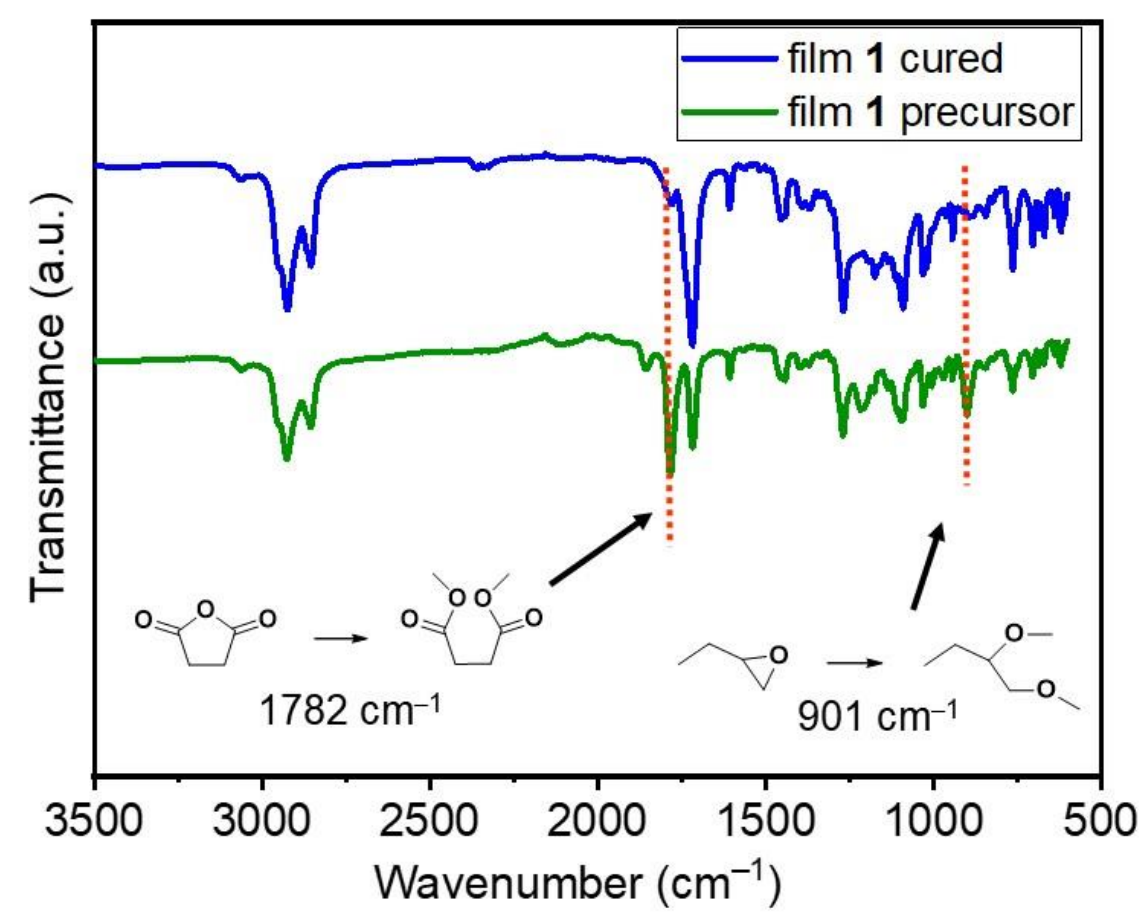

Figure S2. FT-IR spectra of the liquid precursor (green line) and cured film 1 (blue line). The disappearance of the $\mathrm{C}=\mathrm{O}$ stretching peak from acid anhydride $\left(1782 \mathrm{~cm}^{-1}\right)$ and the epoxy $\mathrm{C}-\mathrm{C}$ asymmetric absorption $\left(901 \mathrm{~cm}^{-1}\right)$ were observed after curing the liquid precursor. 
(a)

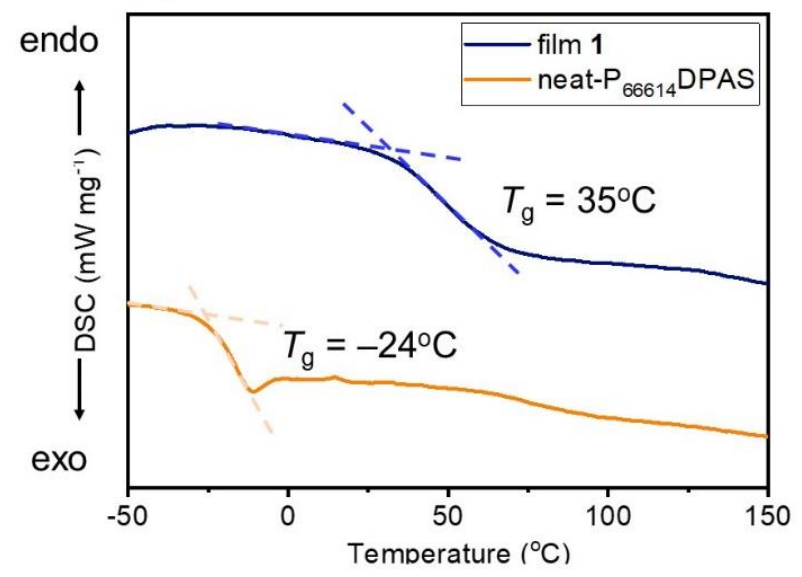

(b)

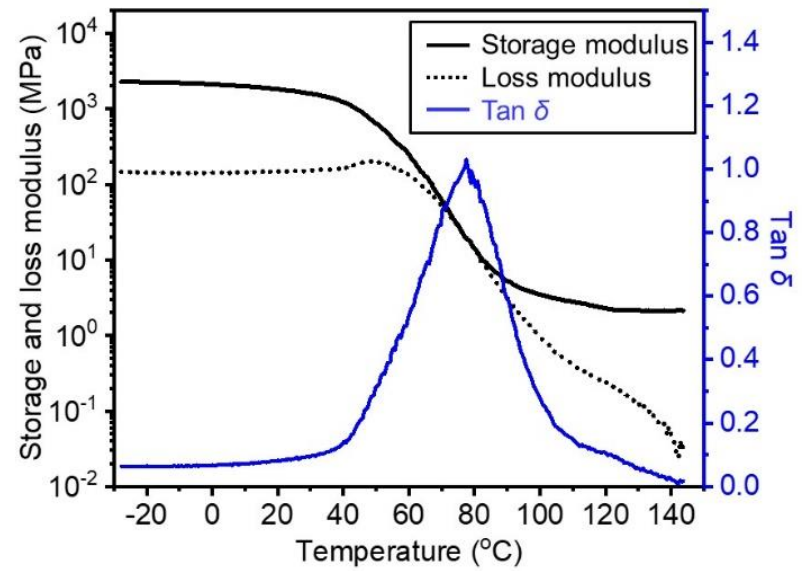

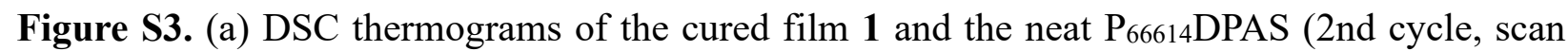
rate: $10{ }^{\circ} \mathrm{C} \min ^{-1}, \mathrm{~N}_{2}$ atmosphere). The glass transition $T_{\mathrm{g}}$ of the film $\mathbf{1}$ and the neat $\mathrm{P}_{66614} \mathrm{DPAS}$ were estimated as $35^{\circ} \mathrm{C}$, and $-24^{\circ} \mathrm{C}$, respectively. (b) Temperature dependence of the storage/loss modulus and loss tangent for film 1 . The thermal gradient was $10^{\circ} \mathrm{C} \mathrm{min}^{-1}$ and then obtained tan $\delta=80^{\circ} \mathrm{C}$. The measurement frequency was $1.0 \mathrm{~Hz}$.

(a)
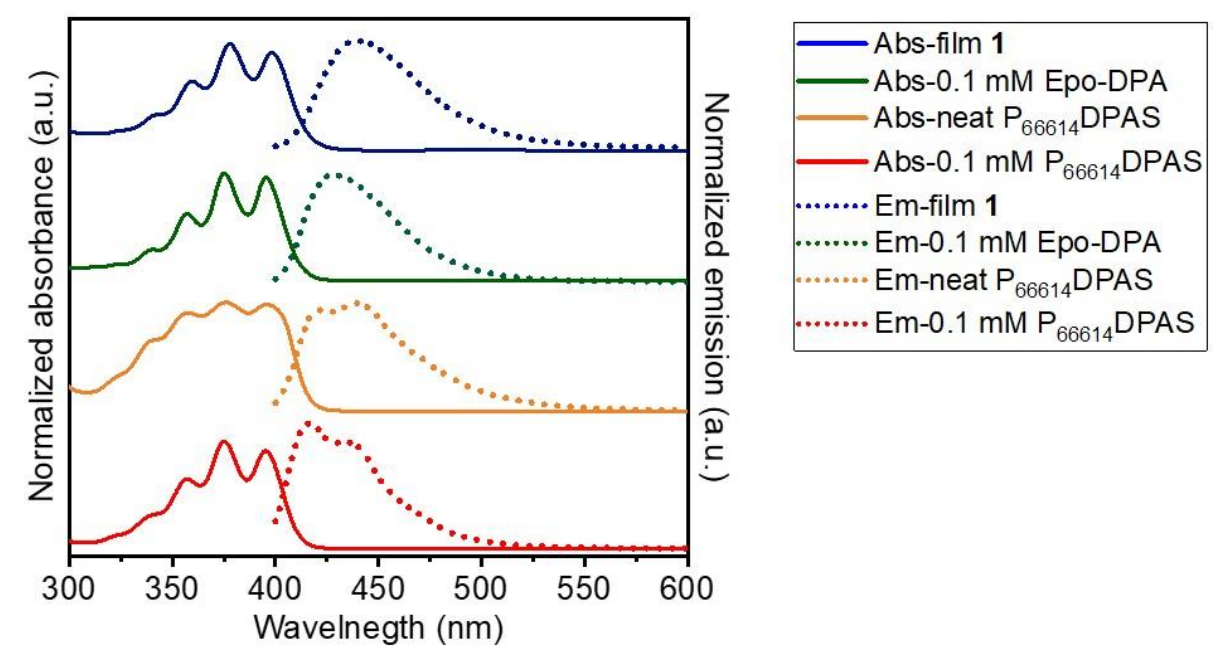

(b)

\begin{tabular}{|c|c|c|c|c|c|}
\hline sample & \multicolumn{3}{|c|}{$\begin{array}{c}\text { absorption peak } \\
(\mathrm{nm})\end{array}$} & \multicolumn{2}{|c|}{$\begin{array}{l}\text { fluorescence peak } \\
(\mathrm{nm})\end{array}$} \\
\hline film 1 & 359.5 & 377.5 & 398 & & \\
\hline $0.1 \mathrm{mM} \mathrm{Epo-DPA}$ & 357 & 375 & 395.5 & & \\
\hline neat $\mathrm{P}_{66614} \mathrm{DPAS}$ & 357.5 & 376 & 396 & 422 & 439 \\
\hline $0.1 \mathrm{mM} \mathrm{P}_{66614} \mathrm{DPAS}$ & 357 & 375 & 395 & 416 & 436 \\
\hline
\end{tabular}

Figure S4. (a) UV-vis absorption spectra (solid line) and fluorescence spectra (dashed line) of film 1 (blue), $0.1 \mathrm{mM}$ Epo-DPA in $\mathrm{CH}_{2} \mathrm{Cl}_{2}$ solution (green), neat $\mathrm{P}_{66614} \mathrm{DPAS}$ (orange) and $0.1 \mathrm{mM}$ P66614DPAS in $\mathrm{CH}_{2} \mathrm{Cl}_{2}$ solution (red). The excitation wavelength was $\lambda_{\text {ex }}=365 \mathrm{~nm}$. (b) A table of the exhibited $\pi-\pi^{*}$ vibronic absorption peaks and fluorescence peaks for the film 1, $0.1 \mathrm{mM}$ EpoDPA in $\mathrm{CH}_{2} \mathrm{Cl}_{2}$ solution, neat $\mathrm{P}_{66614} \mathrm{DPAS}$ and $0.1 \mathrm{mM} \mathrm{P}{ }_{66614} \mathrm{DPAS}$ in $\mathrm{CH}_{2} \mathrm{Cl}_{2}$ solution, respectively. 


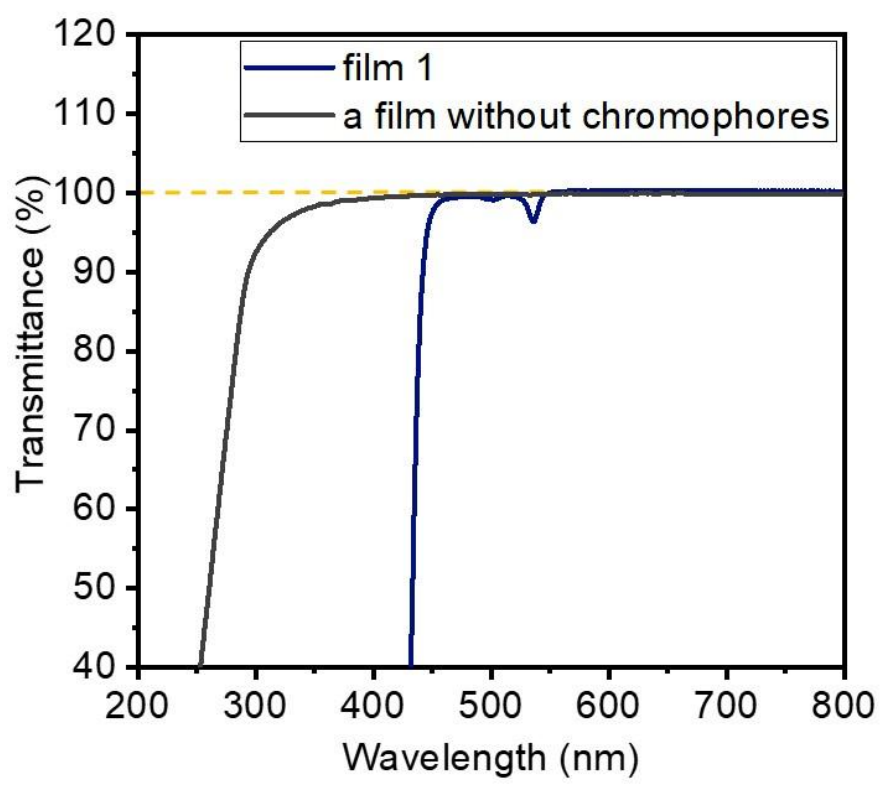

Figure S5. Transmittance spectra of the film 1 (blue line) and a cured film prepared with epoxy A and acid anhydride without any chromophores (gray line). The thickness of the films is $0.05 \mathrm{~mm}$.

Table S2. Absolute fluorescence $\left(\lambda_{\mathrm{ex}}=365 \mathrm{~nm}, \lambda_{\mathrm{em}}=400-600 \mathrm{~nm}\right)$ and phosphorescence $\left(\lambda_{\mathrm{ex}}=\right.$ $532 \mathrm{~nm}, \lambda_{\mathrm{em}}=600-800 \mathrm{~nm}$ ) quantum yields of the films. The size of the film samples is $15 \mathrm{~mm}^{2}$ square and thickness is $0.05 \mathrm{~mm}$. The sensitizer-to-emitter TET efficiency was estimated by the equation $\Phi_{\mathrm{TET}}=1-\Phi_{\mathrm{P}} / \Phi_{\mathrm{P}, 0}$, where $\Phi_{\mathrm{P}}$ and $\Phi_{\mathrm{P}, 0}$ represent phosphorescence quantum yields of the film with (film 1-5) and without (film 11) the emitter, respectively.

\begin{tabular}{cccc}
\hline & \multicolumn{2}{c}{ quantum yields } & \\
\cline { 2 - 3 } films & fluorescence & phosphorescence & $\Phi_{\mathrm{TET}}$ \\
& $(\%)$ & $(\%)$ & $(\%)$ \\
\hline film 1 & 35.1 & 0 & 100 \\
film 2 & 48.0 & 1.2 & 97.8 \\
film 3 & 55.3 & 2.8 & 95.0 \\
film 4 & 57.7 & 3.5 & 93.7 \\
film 5 & 71.2 & 6.5 & 88.3 \\
film 6 & 46.9 & - & - \\
film 7 & 60.7 & - & - \\
film 8 & 67.6 & - & - \\
film 9 & 76.0 & - & - \\
film 10 & 82.9 & - & - \\
film 11 & - & 55.7 & - \\
\hline
\end{tabular}


(a)

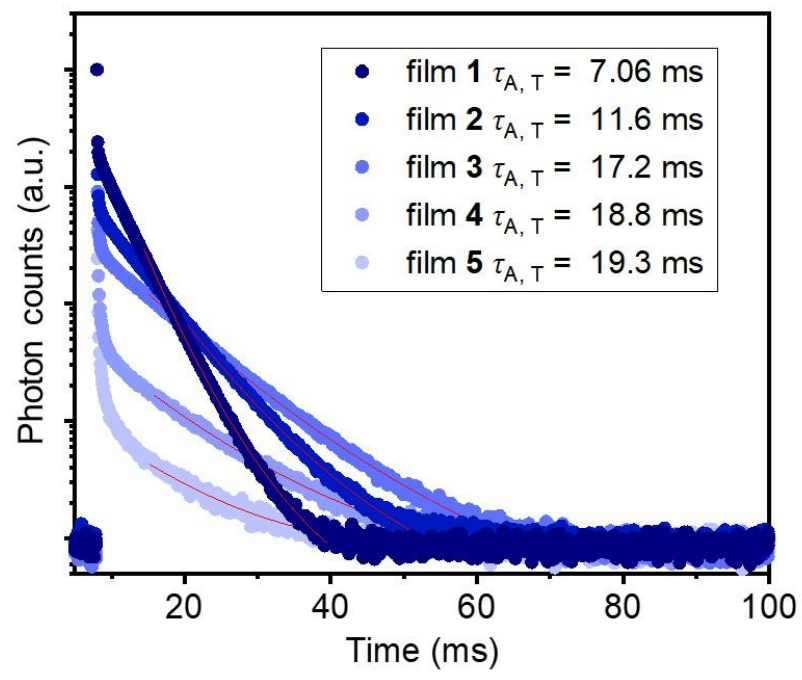

(b)

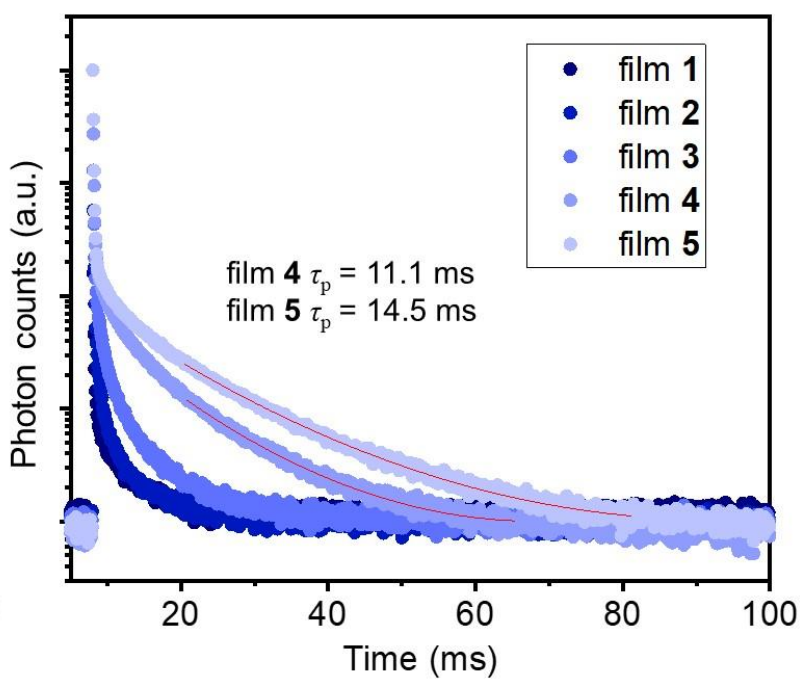

Figure S6. (a) UC emission decays of the films 1-5 under pulsed excitation at $532 \mathrm{~nm}\left(\lambda_{\mathrm{em}}=440\right.$ $\mathrm{nm})$. (b) The long time-scale-range phosphorescence decays of the films 1-5 under pulsed excitation at $532 \mathrm{~nm}\left(\lambda_{\mathrm{em}}=650 \mathrm{~nm}\right)$. The tail fitting of the phosphorescence decays provides the delayed phosphorescence lifetime $(\tau \mathrm{D})$ of $11.1 \mathrm{~ms}$ (film 4) and $14.5 \mathrm{~ms}$ (film 5), respectively.
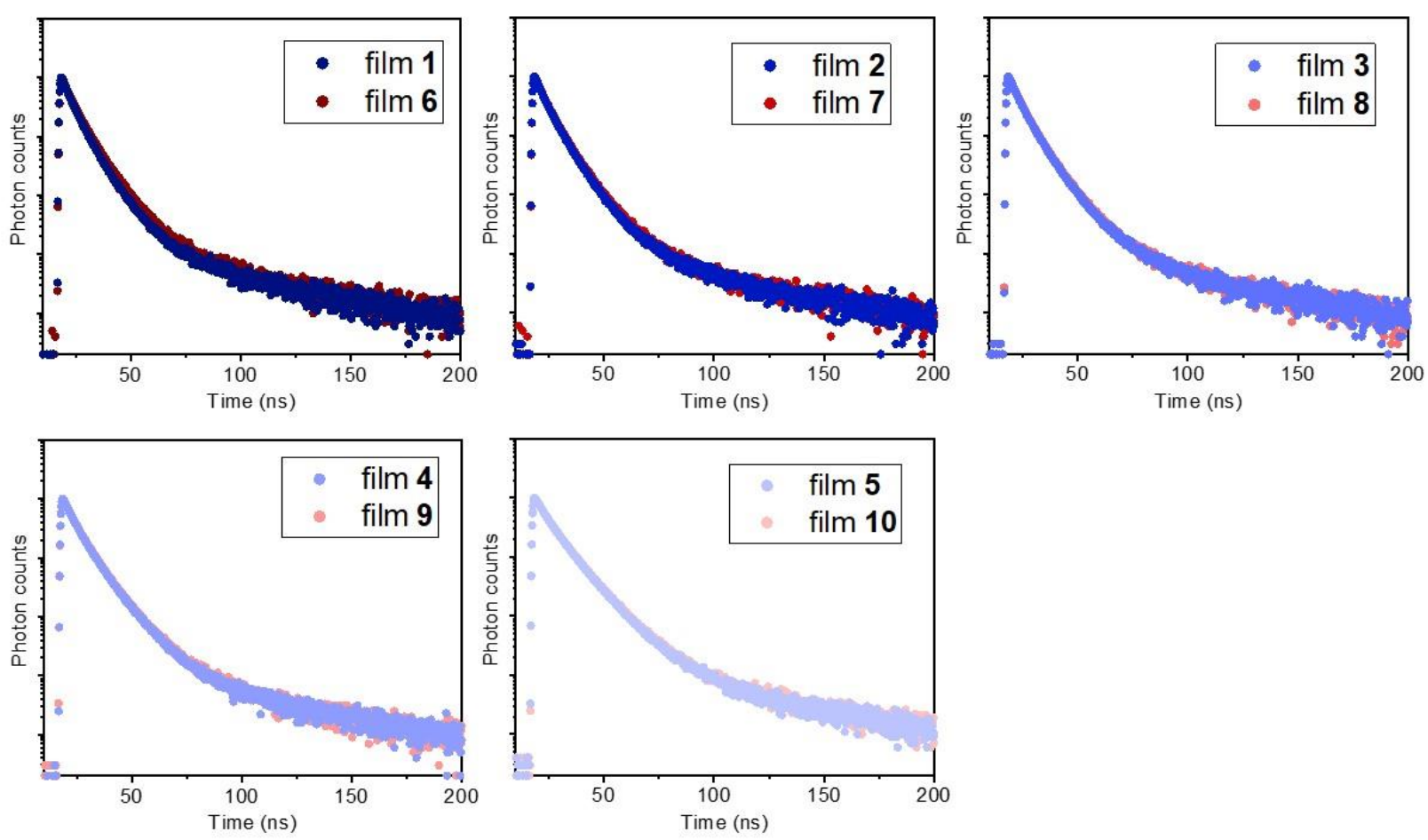

Figure S7. Comparison of fluorescence decays for the films with and without PtOEP. The excitation wavelength was $365 \mathrm{~nm}$ and the detection wavelength was $440 \mathrm{~nm}$. Almost no difference was observed in the fluorescence decays with/without PtOEP, indicating the absence of singlet back energy transfer. 


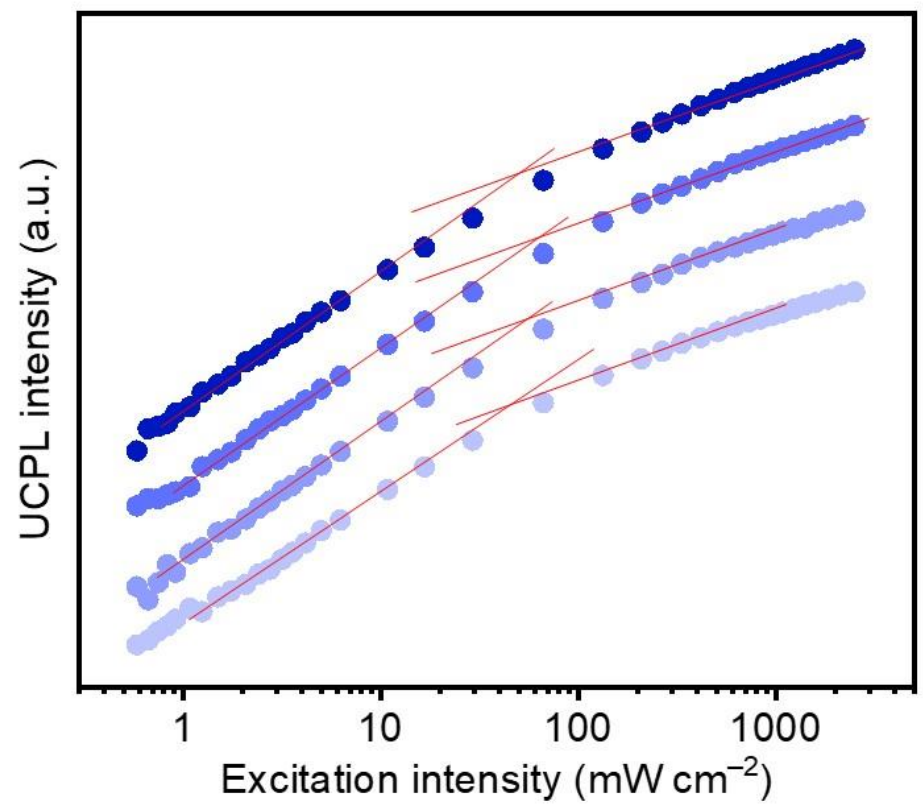

- film $2 I_{\text {th }}=57.1 \mathrm{~mW} \mathrm{~cm}^{-2}$

- film $3 I_{\text {th }}=64.0 \mathrm{~mW} \mathrm{~cm}^{-2}$

- film $4 l_{\text {th }}=55.2 \mathrm{~mW} \mathrm{~cm}^{-2}$

film $5 I_{\text {th }}=47.2 \mathrm{~mW} \mathrm{~cm}^{-2}$

Figure S8. Dependence of UCPL intensity at $440 \mathrm{~nm}$ on the excitation intensity for films $\mathbf{2}-\mathbf{5}$. The dashed lines are fitting results with slopes of 2 and 1 in the low- and high-excitation intensity regimes, respectively.

(a)

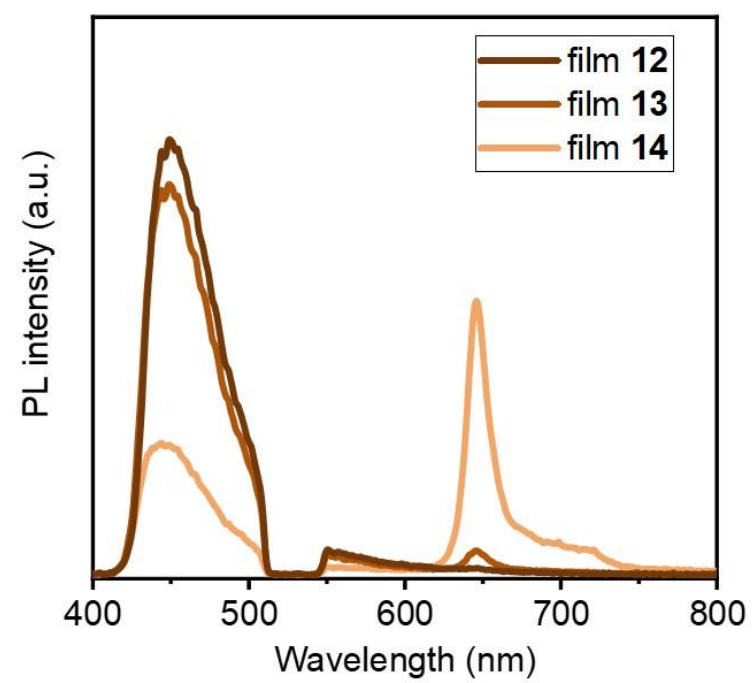

(b)

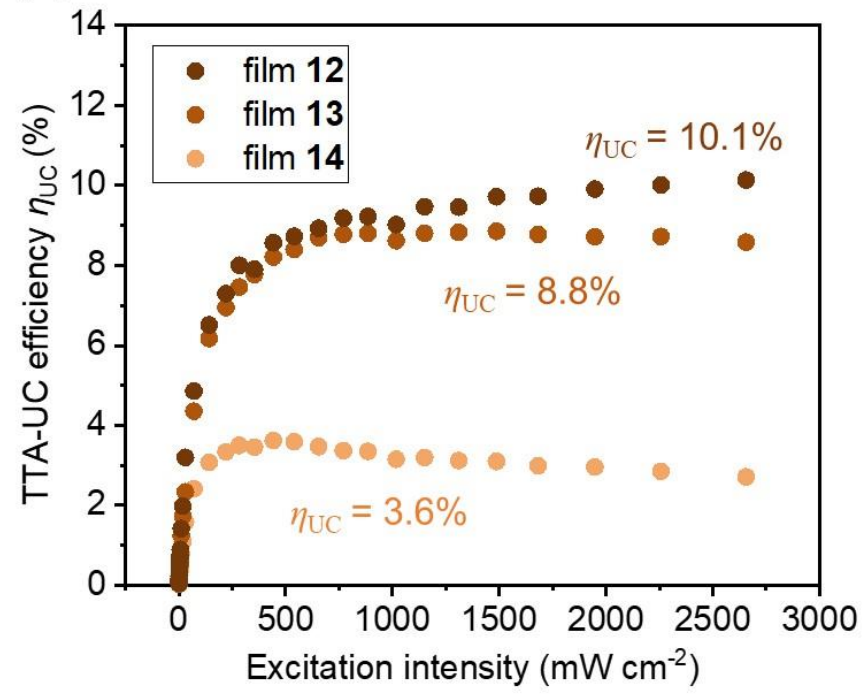

Figure S9. (a) PL spectra of the films 12-14 at an excitation intensity of $1680 \mathrm{~mW} \mathrm{~cm} \mathrm{co}^{-2}$ of the $532 \mathrm{~nm}$ laser. The 520-540 nm notch filter was used to remove the scattered excitation light. (b) TTA-UC efficiency $\eta \mathrm{UC}$ of the films 12-14 measured as a function of excitation intensity at an excitation wavelength of $532 \mathrm{~nm}$. The $\eta_{\mathrm{UC}}$ of each film was determined by the relative method. The thickness of the films, $0.05 \mathrm{~mm}$. 


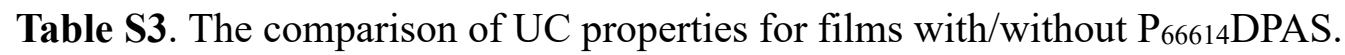

\begin{tabular}{lccc} 
films & $\begin{array}{c}\eta_{\mathrm{UC}} \\
(\%)\end{array}$ & $\begin{array}{c}I_{\text {th }} \\
\left(\mathrm{mW} \mathrm{cm}^{-2}\right)\end{array}$ & $\begin{array}{c}\tau_{\mathrm{A}, \mathrm{T}} \\
(\mathrm{ms})\end{array}$ \\
\hline film 12 & 10.1 & 43.9 & 4.34 \\
(film 1) & 11.4 & 39.1 & 7.06 \\
\hline film 13 & 8.8 & 65.2 & 15.7 \\
(film 3) & 8.8 & 64.0 & 17.2 \\
\hline film 14 & 3.6 & 46.5 & 19.4 \\
(film 5) & 3.98 & 47.2 & 19.3
\end{tabular}

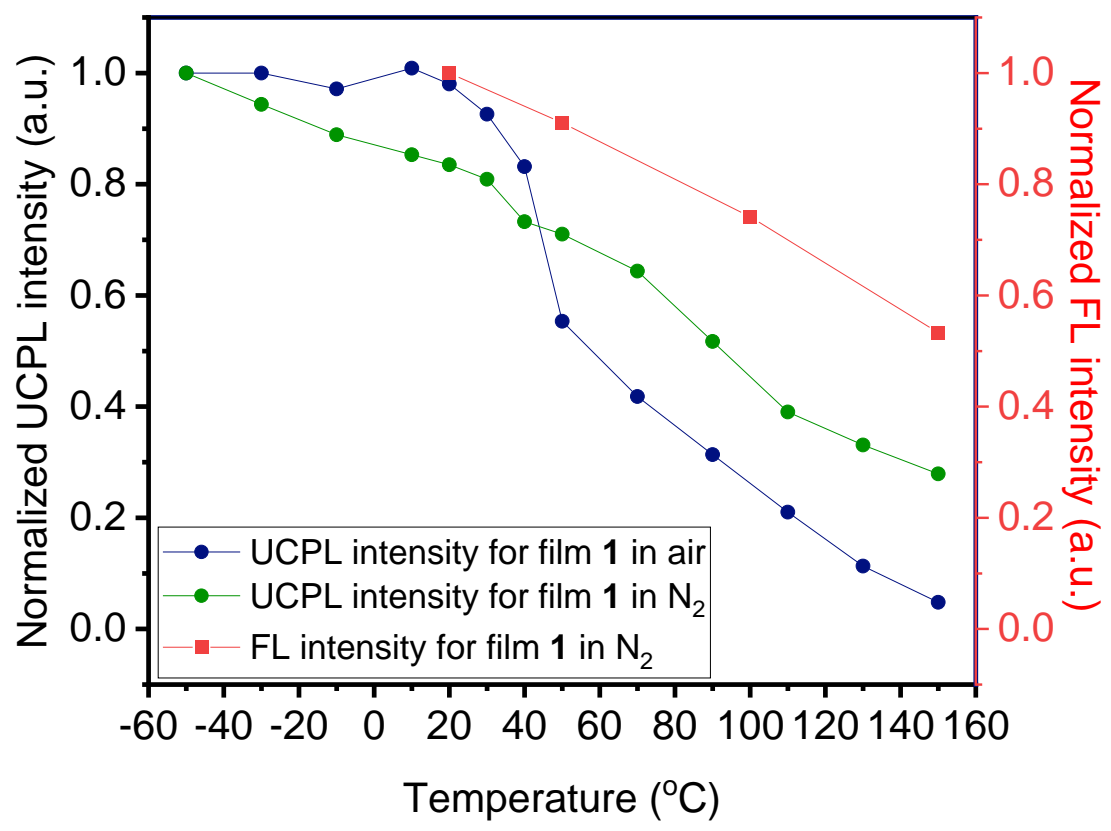

Figure S10. Temperature dependence of the TTA-UC emission intensity for the film 1 under air (blue cycle, the same data of Figure $5 \mathrm{~d}$ ) and under $\mathrm{N}_{2}$ (green cycle). The laser intensity at $532 \mathrm{~nm}$ was kept at $794 \mathrm{~mW} \mathrm{~cm}^{-2}$. The UC emission intensity is normalized to the value at $-50{ }^{\circ} \mathrm{C}$. Temperature dependence of the fluorescence intensity for the film 1 under under $\mathrm{N}_{2}$ (red cycle, $2^{\text {nd }}$ axis). The laser intensity at $375 \mathrm{~nm}$ was kept at $193 \mathrm{~mW} \mathrm{~cm}^{-2}$. The fluorescence intensity is normalized to the value at $20^{\circ} \mathrm{C}$. 


\section{References}

1) Yanai, N.; Suzuki, K.; Ogawa, T.; Sasaki; Y.; Harada, N.; Kimizuka, N. J. Phys. Chem. A, 2019, 123, 10197-10203.

2) Shi, D.; Ren, Y.; Jiang, H.; Lu, J.; Cheng, X. Dalton Trans., 2013, 42, 484-491.

3) Sutar, P.; Suresh, V. M.; Maji, T. K. Chem. Commun., 2015, 51, 9876-9879.

4) Kouno, H.; Ogawa, T.; Amemori, S.; Mahato, P.; Yanai, N.; Kimizuka, N. Chem. Sci., 2016, 7 , 5224-5229. 